\title{
General Psychiatry Global research on cognitive behavioural therapy for schizophrenia from 2000 to 2019: a bibliometric analysis via CiteSpace
}

Xinxing Fei, ${ }^{1}$ Shiqi Wang, ${ }^{2}$ Xiaojiao Zheng, ${ }^{1}$ Kezhi Liu, ${ }^{1}$ Xuemei Liang ${ }^{1}$

To cite: Fei X, Wang S, Zheng $X$, et al. Global research on cognitive behavioural therapy for schizophrenia from 2000 to 2019: a bibliometric analysis via CiteSpace. General Psychiatry 2021;34:e100327. doi:10.1136/ gpsych-2020-100327

Received 05 July 2020 Revised 26 September 2020 Accepted 08 December 2020
Check for updates

(C) Author(s) (or their employer(s)) 2021. Re-use permitted under CC BY-NC. No commercial re-use. See rights and permissions. Published by BMJ.

${ }^{1}$ Psychiatry Department, The Affiliated Hospital of Southwest Medical University, Luzhou, Sichuan, China

${ }^{2}$ Rehabilitation Medicine Department, The Affiliated Hospital of Southwest Medical University, Luzhou, Sichuan, China

Correspondence to Dr Xuemei Liang; liangxuemei013@163.com

\section{ABSTRACT}

Background Cognitive behavioural therapy (CBT) is considered to be an effective treatment for schizophrenia. In recent years, researchers have published clinical research results on CBT for schizophrenia. However, there is currently a lack of bibliometric analysis on CBT for schizophrenia.

Aims To understand the current situation and research trends of CBT for schizophrenia, and to provide valuable information for researchers in this field.

Methods Literature was retrieved from the Web of Science Core Collection database. CiteSpace was used to visually analyse the current status of research on CBT for schizophrenia, as well as trends and points of general interest on this topic.

Results A total of 1151 papers were retrieved. The annual number of publications has increased $417.65 \%$ from 2000 to 2019. Schizophrenia Research was the most active journal. McGorry enjoys considerable influence. The University of London is deemed to be the most active research institution. England and the USA retain the highest scientific productivity in this field. China and Norway might make more contributions to this field in the future. The most important research topics are randomised controlled trials of CBT for schizophrenia, metaanalysis, scale selection and research on the improvement of quality of life. Results from the following keywords 'psychoeducation', 'insomnia', 'individual', 'mental illness', 'major depressive disorder', 'efficacy', 'internalised stigma' and 'remediation' indicated new research frontiers in this field. Conclusions The field of CBT for schizophrenia is progressing and has great potential. The level and quality of research in this field is high. The proposal of research hotspots and frontiers serves as a direction for researchers in this field. Researchers around the world should strengthen their cooperation and communication to promote further development of this field.

\section{INTRODUCTION}

Schizophrenia is a complex and strongly inherited mental illness, which severely affects the quality of life. ${ }^{1}$ Approximately $1 \%$ of the global population suffers from schizophrenia, and the incidence rate is similar across different countries, cultural groups and genders. ${ }^{2}$ In recent years, some progress has been made in the diagnosis and treatment of schizophrenia. However, the high recurrence rate remains a major challenge. ${ }^{3}$ Therefore, it is vital to promote research in this field, enabling the development of effective treatments for schizophrenia.

Bibliometrics is the application of quantitative analysis and statistics to publications such as journal articles and their accompanying citation counts to estimate the impact of literature on future research. ${ }^{45}$ CiteSpace is an information visualisation software programme based on cocitation analysis theory and routing network algorithms. ${ }^{6}$ CiteSpace can be used for quantitative analysis of literature in specific fields to explore the key paths and knowledge nodes of discipline evolution and for exploration of the frontiers of discipline development using visualisation techniques. ${ }^{7}$

Cognitive behavioural therapy (CBT) is considered to be an effective treatment for schizophrenia. ${ }^{8}$ A large number of researchers in various countries have published clinical research results on CBT for schizophrenia, including the differences between CBT and other psychosocial treatments, ${ }^{9} 10$ the influence of drug dose on the efficacy of $\mathrm{CBT}^{11}$ and comparisons of the efficacy of antipsychotic drugs and CBT. ${ }^{12}$ However, there is currently a lack of bibliometric analysis on CBT for schizophrenia.

Therefore, in the current study, we sought to understand the current status of research on CBT for schizophrenia, as well as trends and points of general interest on this topic over the past 20 years. We used CiteSpace software to visually analyse the results, aiming to provide valuable information for researchers in this field.

\section{METHODS}

Retrieval strategy

Literature was retrieved from the Web of Science (WOS) Core Collection database. ${ }^{13}$ 


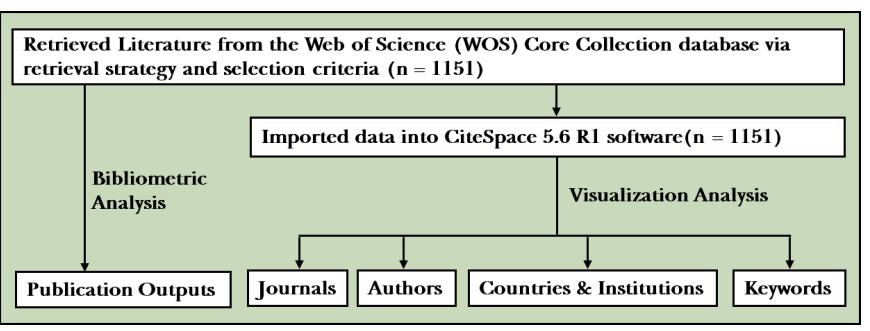

Figure 1 Flowchart of information through different phases of this bibliometric analysis.

We used the following retrieval strategy: TS $=($ 'cognitive behavioral therap*' OR 'cognitive behavior therap*' OR 'cognitive therap*' OR 'cognition therap*' OR 'cognitive psychotherap*') AND TS=('schizophrenic disorde*' OR 'schizophren*'). The time span was 2000 to 2019 (last retrieval date: 23 December 2019).

\section{Selection criteria}

The index was Science Citation Index Expanded (SCIExpanded).${ }^{14}$ There was no strict restriction on the inclusion language of the articles. Due to the limitation of the WOS, there exists a lack of languages, such as Chinese and Korean. The articles are strictly retrieved according to the term words contained in the retrieval strategy, and the retrieval results cover almost all the articles in this field. All the results were included in CiteSpace for analysis (figure 1).

\section{Data processing}

We recorded the most commonly used bibliometric indicators, including a number of published papers, the average citation frequency and h-index of journals and authors in this field, and the impact factor (IF) of journals. ${ }^{15} 16$ The full records of the retrieved data were exported in plain text format, and the data were imported into CiteSpace 5.6 R1 software. The above processes were completed independently by two researchers (XX and SQ). If there were disagreements between the two researchers, a third researcher $(\mathrm{XJ})$ was consulted to reach a consensus.

\section{Parameter setting}

Parameter settings of the software were as follows: 'time slicing' was 2000-2019, and the 'years per slice' value was 1 . The 'node type' selected 'author', 'country', 'institution' and 'keyword', respectively. The value of 'top N' depended on the 'node type'. In general, 'top N' was 20. While 'node type' was 'keyword', 'top N' was set to 50. Other parameters were system default values.

\section{Basic concepts of CiteSpace}

In the generated map, each node represents an author (country/territory, institution, keyword). Links between the nodes represent the connection or cooperation between the authors (countries/territories, institutions, keywords) ${ }^{17}$ If the node is bright red, it represents a sharp increase in the amount of literature published by the author (country/territory, institution) in recent years or represents a sharp increase in the frequency of keywords. ${ }^{18}$ The cluster map can be used to classify nodes with similar characteristics. ${ }^{7}$

\section{RESULTS}

\section{Publication outputs}

A total of 1151 publications were retrieved, and the most common publication language was English (91.83\%). Article was the most common publication type (70.49\%). The annual number of publications increased from 17 in 2000 to 88 in 2019, representing an increase of $417.65 \%$. From 2000 to 2006, the annual literature growth rate was relatively rapid, with an average annual increase of 6.33 papers. From 2007 to 2012, the annual literature growth rate was relatively slow, with an average annual increase of 4.6 papers. From 2013 to 2019, the annual literature growth rate gradually levelled off (figure 2).

\section{Journals}

In total, 236 journals published research on CBT for treating schizophrenia. The top 10 journals published 419 papers in this field, accounting for $36.40 \%$ of the total publications. The top journal was Schizophrenia Research, with 99 publications, an h-index value of 38 and an IF of 4.569. Among the top 10 journals, only one journal had an IF of $<2.000$. And four journals had an IF of $>5.000$ (table 1).

\section{Authors}

In total, 4016 authors published literature in this field. The top 10 authors published a total of 245 articles in this field, accounting for $21.29 \%$ of the total publications. The top-ranked author was Turkington, with 33 publications, and an h-index value of 14 . McGorry had an h-index value of 22, which was the highest among the top 10 authors (table 2).

The top five authors ranked by co-occurrence counts were Turkington (20), Dunn (18), Morrison (16), Kingdon (15) and Freeman (13). The top five authors ranked by centrality were Peters (0.17), Fowler (0.15), Dunn (0.14), Wykes (0.12) and Waters (0.09). No author showed a sudden increase in the number of published literature in the last 5 years (figure $3 \mathrm{~A}$ ).

\section{Countries and institutions}

Over the past 20 years, researchers in a total of 61 countries/territories published studies about CBT for schizophrenia. Table 3 shows the top 10 countries/territories in this field. Figure 4A shows a coauthorship map of countries, resulting in 35 nodes and 42 links. The top five countries/territories ranked by co-occurrence counts were the USA $(n=356)$, England $(n=326)$, Germany $(\mathrm{n}=144)$, Australia $(\mathrm{n}=102)$ and Canada $(\mathrm{n}=85)$. The top five countries/territories ranked by centrality were Netherlands (1.23), Belgium (0.91), Spain (0.81), Austria (0.56) and Canada (0.51). China and Norway showed a sudden increase in the amount of published literature in the last 5 years (figure $3 \mathrm{~B}$ ). 


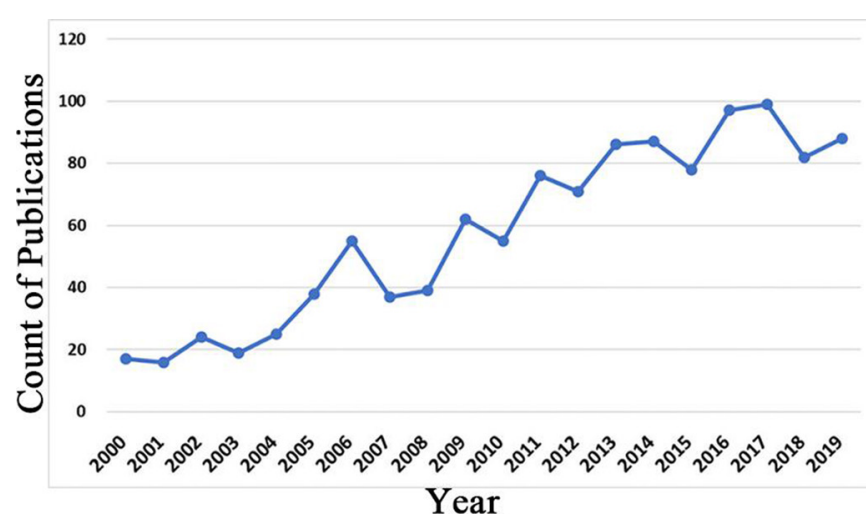

Figure 2 Trends in the count of publications from 2000 to 2019 in the field of CBT for schizophrenia. CBT, cognitive behavioural therapy.

A total of 1477 research institutions published relevant literature, and the top 10 institutions are shown in table 4. Figure 4B shows a coauthorship map of institutions, resulting in 180 nodes and 249 links. The top five institutions ranked by co-occurrence counts were the University of Manchester $(n=113)$, King's College London $(n=90)$, the University of Melbourne $(n=45)$, the University of California, San Diego $(n=34)$ and the University of Southampton $(\mathrm{n}=25)$. The top five institutions ranked by centrality were the University of California, Los Angeles (0.46), Newcastle University (0.45), the University of Melbourne (0.36), Harvard University (0.24) and Orygen the National Centre of Excellence in Youth Mental Health (0.23). The Parnassia Psychiatric Institute and the University of Sussex showed a sudden increase in the amount of published literature in the last 5 years (figure $3 \mathrm{C}$ ).

\section{Keywords}

Figure 5A shows the keyword co-occurrence network map, resulting in 278 nodes and 581 links. Removing the words related to 'cognitive behavioural therapy' and 'schizophrenia', including 'schizophrenia', 'cognitive behavioural therapy', 'cognitive therapy', 'cognitive behaviour therapy', 'psychotherapy' and 'therapy'. The top 15 keywords ranked by frequency were 'randomised controlled trial $(\mathrm{n}=358)$ ', 'psychosis $(\mathrm{n}=287)$ ', 'follow up $(\mathrm{n}=154)$ ', 'depression $(\mathrm{n}=146)$ ', 'intervention $(\mathrm{n}=128)^{\prime}$, 'meta-analysis $(\mathrm{n}=106)$ ', 'disorder $(\mathrm{n}=100)$ ', 'people $(\mathrm{n}=100)$ ', 'scale $(\mathrm{n}=97)$ ', 'quality of life $(\mathrm{n}=86)$ ', '1st episode psychosis $(\mathrm{n}=75)$ ', 'ultra-high risk $(\mathrm{n}=73)$ ' and 'delusion $(\mathrm{n}=73)$ '. The top 10 keywords ranked by centrality were 'program $(0.24)$ ', 'severe mental illness $(0.22)$ ', '1st episode schizophrenia (0.18)', 'high risk $(0.18)$ ', 'efficacy $(0.14)$ ', 'neurocognitive deficit $(0.14)$ ', 'trial (0.13)', 'family intervention (0.13)', 'persecutory delusion (0.12)' and 'early intervention (0.11)'. Figure 5B shows the keyword co-occurrence cluster map resulted in 11 clusters via clustering analysis. The frequency of the following keywords suddenly increased in the last 5 years: 'psychoeducation', 'insomnia', 'individual', 'mental illness', 'major depressive disorder', 'efficacy', 'internalised stigma' and 'remediation' (figure 3D).

\section{DISCUSSION}

\section{Main findings}

The changes in the number of publications each year can roughly show the development trend in the field of CBT for schizophrenia. The number of published articles increased year by year from 2000 to 2012 and gradually stabilised from 2013 to 2019. These findings indicate that the field is maturing gradually and has potential for further development.

There are many articles published in various journals about CBT for schizophrenia. The present analysis of journals revealed that $36.40 \%$ of studies were published in the top 10 journals. Of these, more than half (55.37\%) of the relevant papers were published in Schizophrenia Research, Schizophrenia Bulletin and Psychiatry Research. This indicates that the top three journals are the most active journals because they publish a large number of

Table 1 Top 10 journals in field of CBT for schizophrenia

\begin{tabular}{clllll}
\hline Rank & Journal & Publications & $\begin{array}{l}\text { Times cited } \\
\text { (per article ) }\end{array}$ & h-index & IF (2019) \\
\hline 1 & Schizophrenia Research & 99 & 40.18 & 38 & 4.569 \\
\hline 2 & Schizophrenia Bulletin & 83 & 53.83 & 34 & 7.289 \\
\hline 3 & Psychiatry Research & 50 & 15.4 & 15 & 2.208 \\
\hline 4 & Journal of Nervous and Mental Disease & 34 & 28.3 & 20 & 1.859 \\
\hline 5 & Psychological Medicine & 33 & 42.09 & 19 & 5.641 \\
\hline 6 & British Journal of Psychiatry & 31 & 45.29 & 16 & 7.233 \\
7 & Early Intervention in Psychiatry & 31 & 10.24 & 10 & 3.323 \\
8 & Cochrane Database of Systematic Reviews & 20 & 34.45 & 11 & 7.755 \\
\hline 9 & Acta Psychiatrica Scandinavica & 19 & 37.21 & 13 & 4.694 \\
\hline 10 & BMC Psychiatry & 19 & 9.68 & 9 & 2.666 \\
\hline
\end{tabular}

CBT, cognitive behavioural therapy; IF, impact factor. 
Table 2 Top 10 authors in the field of CBT for schizophrenia

\begin{tabular}{|c|c|c|c|c|c|}
\hline Rank & Author & Publications & Institution & $\begin{array}{l}\text { Times cited } \\
\text { (per article ) }\end{array}$ & h-index \\
\hline 1 & Turkington & 33 & Newcastle University & 36.33 & 14 \\
\hline 3 & Kingdon & 28 & University of Southampton & 38.07 & 13 \\
\hline 4 & Morrison & 26 & University of Manchester & 52.58 & 16 \\
\hline 7 & McGorry & 22 & Orygen Youth Health, PACE Clinic & 99.09 & 21 \\
\hline 8 & Freeman & 20 & University of Oxford & 25.15 & 13 \\
\hline 9 & Kuipers & 20 & Kings College London & 25.15 & 13 \\
\hline 10 & Mueser & 20 & Dartmouth College School Medicine & 61.75 & 11 \\
\hline
\end{tabular}

The institution was extracted from the author's published paper, which may be different from the current working address of the author. CBT, cognitive behavioural therapy.

papers and have a substantial impact in the field of CBT for schizophrenia. Among the top 10 active journals, the results revealed four journals with IF $>5.000$, indicating that the level and quality of research in this field is high.

Peters, from the King's College London, was the author with the highest value of centrality. The result indicated that Peters had the closest academic communication in the field. Turkington, from Newcastle University, was the author with the highest number of published articles. McGorry, from Orygen the National Centre of Excellence in Youth Mental Health, only published 22 publications in the field but had an h-index value of 21, and an average publication citation frequency of 99.09. The h-index is a hybrid quantitative index used to evaluate the quantity and level of academic output of researchers. ${ }^{19}$ Therefore, the results indicated that McGorry's papers were influential in this field. The most cited article published by McGorry was 'Randomized controlled trial of interventions designed to reduce the risk of progression to firstepisode psychosis in a clinical sample with subthreshold symptoms', ${ }^{20}$ which had an important impact in the field. Because the results of the study revealed that more specific pharmacotherapy and psychotherapy can reduce the possibility of ultra-high-risk young people transitioning to mental illness involving psychosis, the study provided an important foundation for further development in the field. Using burst analysis, we identified authors whose publications have increased sharply in recent years.

\begin{tabular}{|c|c|c|c|}
\hline Institutions & Year & Strength Begin & $2000-2019$ \\
\hline st Psychiat & 2000 & 6.82522001 & 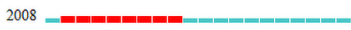 \\
\hline Univ Pittsburgh & 2000 & 3.31762004 & $2012=$ \\
\hline Massachusetts Gen Hosp & 2000 & 3.33452004 & 2013 \\
\hline Yale Univ & 2000 & 3.71572005 & 2009 \\
\hline Univ Cologne & 2000 & 3.8422005 & 2011 \\
\hline Univ N Carolina & 2000 & 3.26382005 & 2009 \\
\hline Univ Newcastle & 2000 & 3.62712007 & $2012=$ \\
\hline Univ Melbourne & 2000 & 5.83582008 & $2011=$ \\
\hline Univ Cambridge & 2000 & 3.2282010 & $2012=$ \\
\hline Columbia Univ & 2000 & $3.3603 \quad 2010$ & 2011 \\
\hline Kings Coll London & 2000 & 5.52192014 & $2016=$ \\
\hline Univ Hamburg & 2000 & 3.96942015 & $2017=$ \\
\hline South London \& Maudsley NHS Fdn Trust & 2000 & 4.13832015 & $2019=-=$ \\
\hline Parnassia Psychiat Inst & 2000 & 3.3122016 & 2019 \\
\hline Univ Sussex & 2000 & $3.4844 \quad 2017$ & $2019=$ \\
\hline
\end{tabular}

A

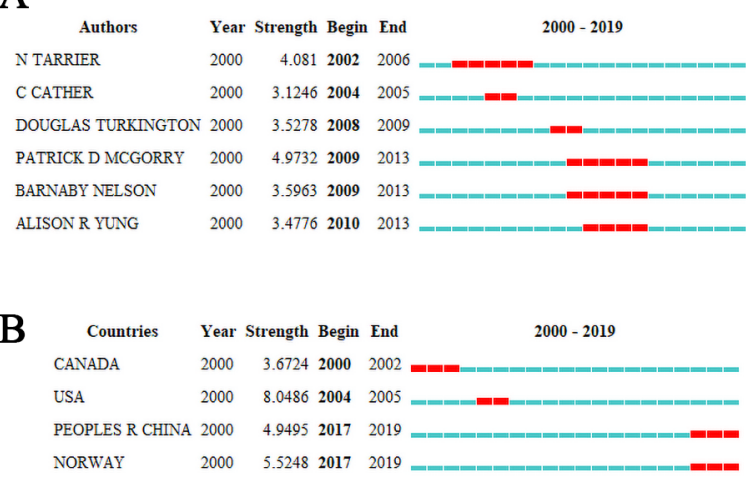

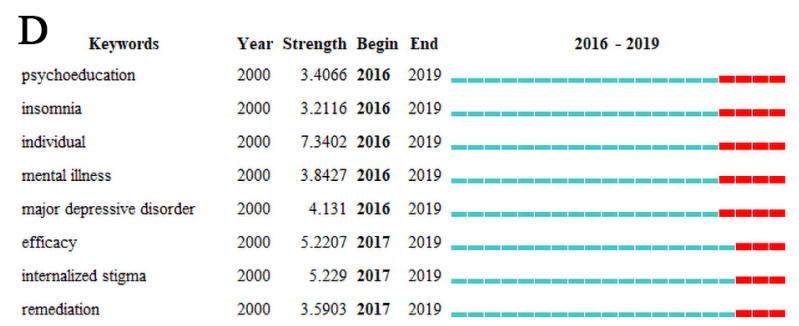

Figure 3 The strongest bursts. (A) Authors with the strongest bursts from 2000 to 2019. (B) Countries with the strongest bursts from 2000 to 2019. (C) Institutions with the strongest bursts from 2000 to 2019. (D) Keywords with the strongest bursts from 2016 to 2019. 
Table 3 Top 10 countries/territories in field of CBT for schizophrenia

\begin{tabular}{cll}
\hline Rank & Country/Territory & Publications \\
\hline 1 & USA & 356 \\
2 & England & 328 \\
3 & Germany & 146 \\
4 & Australia & 104 \\
5 & Canada & 88 \\
6 & Switzerland & 65 \\
7 & Netherlands & 63 \\
8 & Spain & 45 \\
9 & France & 42 \\
10 & Italy & 36 \\
\hline
\end{tabular}

CBT, cognitive behavioural therapy.

However, no author's paper in this field was found to show sharp increases in the last 5 years. Moreover, the author with the highest number of published articles was not the author with the highest centrality. These results indicate that communication and cooperation among authors in this field should be increased further.

Country/territory analysis revealed that research on CBT for schizophrenia is related to the economic and scientific status of each country or territory. Researchers in England and the USA have published the most research in this field. Countries in Europe have closer

A
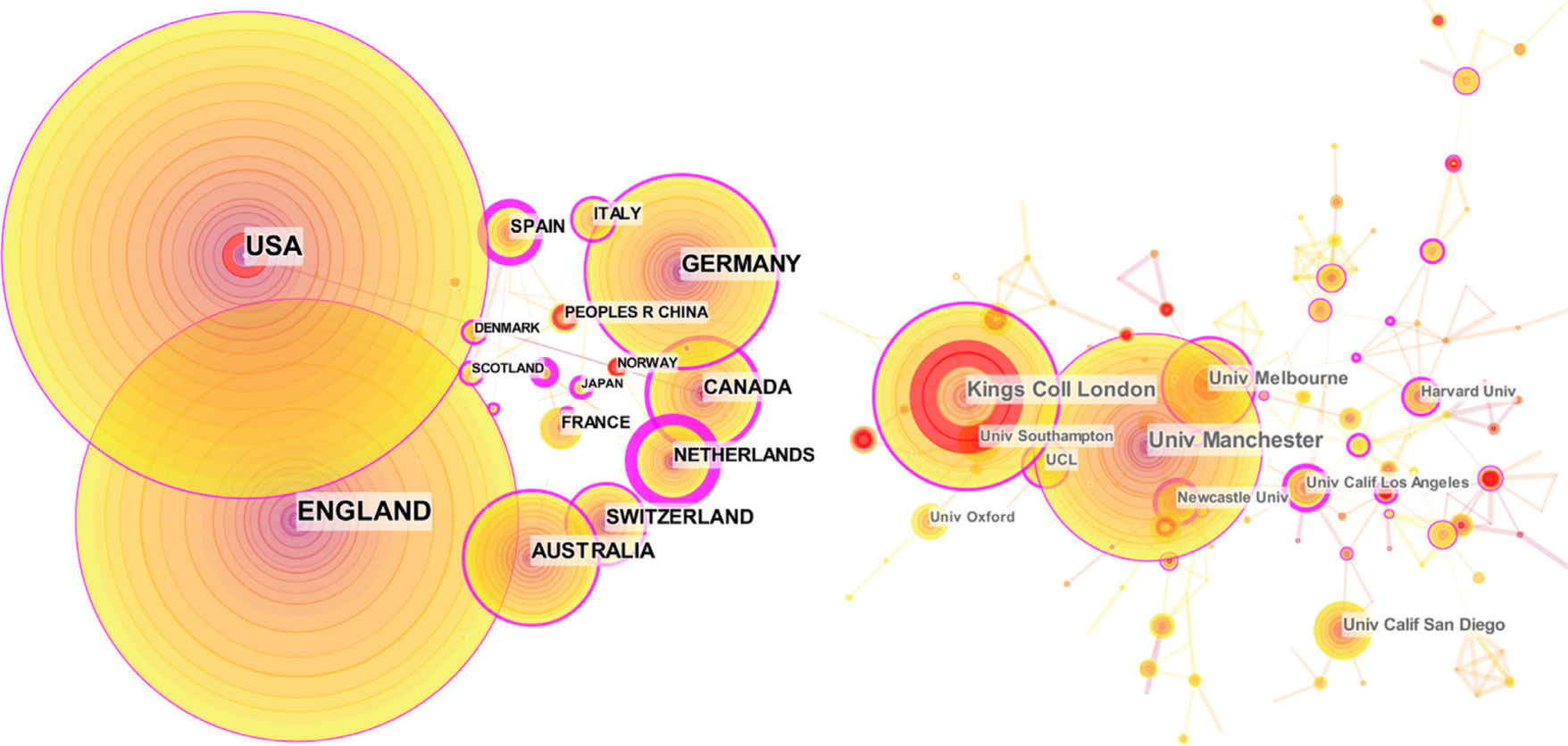

\begin{tabular}{cll}
\hline Table 4 & \multicolumn{2}{l}{ Top 10 institutions in field of CBT for schizophrenia } \\
\hline Rank & Institution & Publications \\
\hline 1 & University of London & 131 \\
2 & Kings College London & 115 \\
3 & University of Manchester & 114 \\
4 & University of California System & 75 \\
5 & University of Melbourne & 53 \\
6 & $\begin{array}{l}\text { Orygen the National Centre } \\
\text { of Excellence in Youth Mental } \\
\text { Health }\end{array}$ & 44 \\
7 & Newcastle University & 40 \\
8 & $\begin{array}{l}\text { University of California, San } \\
\text { Diego }\end{array}$ & 40 \\
9 & Harvard University & 37 \\
10 & $\begin{array}{l}\text { South London Maudsley NHS } \\
\text { Trust }\end{array}$ & 33 \\
\hline
\end{tabular}

CBT, cognitive behavioural therapy.

academic communication than those in America and Asia. However, burst analysis revealed that the amount of literature published by researchers in China and Norway has increased sharply in recent years, indicating that the overall impact of their papers is increasing. Researchers in these countries may make further contributions to the field of CBT for schizophrenia in the future.

Countries/territories and institutions with the most published literature have the highest scientific productivity

B

Figure 4 Maps of literature published by countries/institutions from 2000 to 2019 in the field of CBT for schizophrenia. (A) Coauthorship map of countries. (B) Coauthorship map of institutions. Each node represents an author (country/territory, institution). Links between the nodes represent the connection or cooperation between the authors (countries/territories, institutions). CBT, cognitive behavioural therapy. 
A

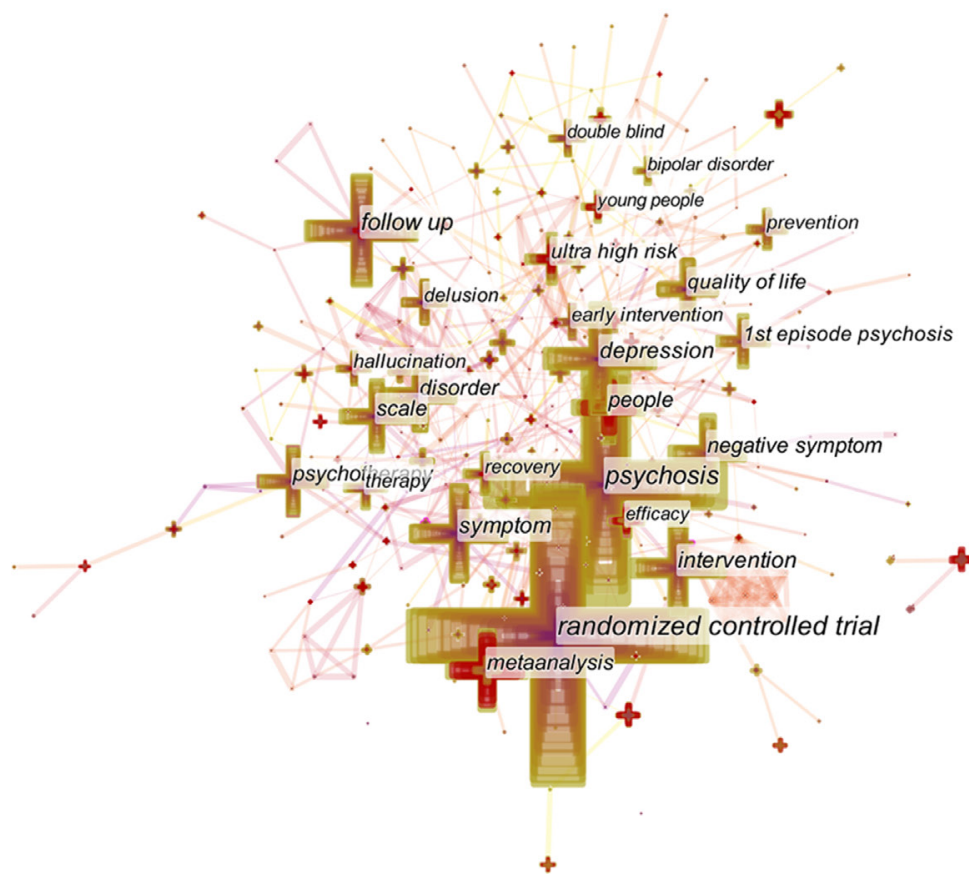

B

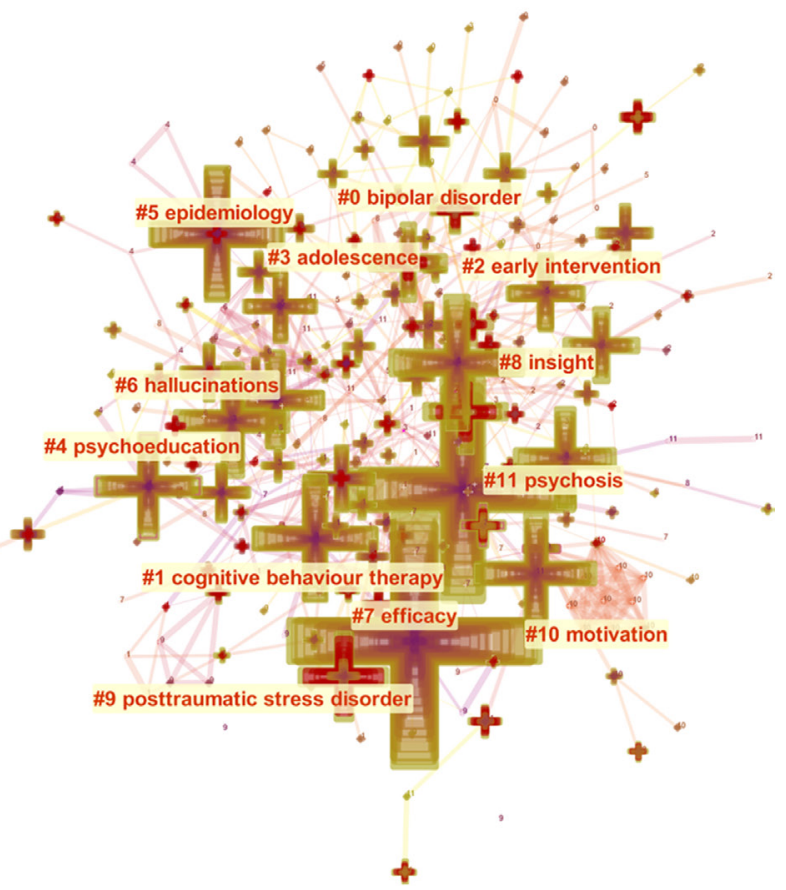

Figure 5 Maps of keyword co-occurrence in literature from 2000 to 2019 in the field of CBT for schizophrenia. (A) The keyword co-occurrence network map. Each node represents a keyword. Links between the nodes represent the connection between the keywords. (B) The keyword co-occurrence cluster map. The cluster map can be used to classify nodes with similar characteristics. The smaller the cluster number, the more keywords it contains. CBT, cognitive behavioural therapy.

in this field. Analysis of research institutions revealed that the institution with the most published literature was the University of London. In addition, the institution with the closest academic communication in this field was the University of California, Los Angeles. Consistent with the author analysis results, this finding suggests that countries and institutions should strengthen their cooperation and communication to promote further development of this field. The amount of literature published by the Parnassia Psychiatric Institute and the University of Sussex has increased sharply in the past 5 years, suggesting that the research direction of these institutions is increasingly focused on CBT for schizophrenia and that they are likely to contribute substantially to progress in this field in the future.

The analysis of keywords helps researchers identify important new topics in the field. The keyword co-occurrence network map can make the presentation of these topics more intuitive. The relationships among keywords in the current study were very close. The current research hot topics in this field are still focused on randomised controlled trials of CBT for schizophrenia $^{21}$, meta-analysis ${ }^{22}$, rating scale $^{23}$, improvement of quality of life ${ }^{24}$ and ultra-high risk status. ${ }^{25}$ Burst analysis can help researchers understand future research frontiers. Research frontiers are considered to be appropriate choices for emerging research teams. In our study, results from the following keywords indicated potential research frontiers: 'psychoeducation', 'insomnia', 'individual', 'mental illness', 'major depressive disorder', 'efficacy', 'internalised stigma' and 'remediation'. Keywords can be better classified by cluster analysis. Researchers are also able to observe the research trends of different topics and better understand the research direction of CBT for schizophrenia according to the results of the cluster analysis. In the present study, the newest clusters on the keyword co-occurrence cluster map were bipolar disorder (2010), motivation (2008), early intervention (2007), adolescence (2007) and hallucinations (2007). We found that researchers were increasingly focused on the age of onset ${ }^{26}$, intervention time ${ }^{27}$ and complex clinical symptoms. ${ }^{28}$

\section{Limitations}

Our bibliometric analysis had some limitations that should be considered. In the current study, data were searched only from the WOS. The retrieval strategy may not have identified all of the relevant studies in this field. In addition, the current study only included studies published in journals that are indexed, excluding grey literature. ${ }^{29}$ Finally, we did not use all of the available bibliometric indicators, such as the $\mathrm{h}^{2}$-index and R-index. ${ }^{30}$ These issues should be addressed in future studies.

\section{Implications}

The field of cognitive behavioral therapy for schizophrenia is maturing, with great potential and broad prospects. The quality of research in this field is high. The top journals in this field can be the target journals for researchers. Additionally, the topics of special interest and novel studies in this field are indicative of the future directions in CBT for schizophrenia research. However, cooperation among countries, institutions and 
researchers in this field is relatively sparse. Researchers from various countries should strengthen cooperation to promote further development in this field. Researchers can also use the results of this study to find potential collaborators. As a software used in scientific literature to identify new trends and developments in research development, CiteSpace is also expected to play an active role in related fields such as mental health in the future.

Acknowledgements We thank Benjamin Knight, MSc., from Liwen Bianji, Edanz Editing China (www.liwenbianji.cn/ac), for editing the English text of a draft of this manuscript.

Contributors X-ML designed the study. X-XF and S-QW managed the literature searches and analyses. K-ZL, X-XF and X-JZ undertook the CiteSpace software, and $\mathrm{X}-\mathrm{XF}$ and $\mathrm{S}-\mathrm{QW}$ wrote the first draft of the manuscript. All authors contributed to and have approved the final manuscript.

Funding This work was supported by Sichuan science and technology program (grant number 2017JY0322).

Competing interests None declared.

Patient consent for publication Not required.

Provenance and peer review Not commissioned; externally peer reviewed.

Data availability statement Data are available on reasonable request. Data imported into CiteSpace were downloaded from the Web of Science Core Collection database (http://isiknowledge.com/) on 23 December 2019.

Open access This is an open access article distributed in accordance with the Creative Commons Attribution Non Commercial (CC BY-NC 4.0) license, which permits others to distribute, remix, adapt, build upon this work non-commercially, and license their derivative works on different terms, provided the original work is properly cited, appropriate credit is given, any changes made indicated, and the use is non-commercial. See: http://creativecommons.org/licenses/by-nc/4.0/.

\section{REFERENCES}

1 Mueser KT, McGurk SR. Schizophrenia. Lancet 2004;363:2063-72.

2 Sytema S. The epidemiology of schizophrenia. Schizophr Res 2010;40:503-03.

3 Galderisi S, Färden A, Kaiser S. Dissecting negative symptoms of schizophrenia: history, assessment, pathophysiological mechanisms and treatment. Schizophr Res 2017;186:1-2.

4 Cooper ID. Bibliometrics basics. J Med Libr Assoc 2015;103:217-8.

5 Reuters T. Whitepaper using Bibliometrics: a guide to evaluating research performance with citation data, 2008.

6 Wang S-Q, Gao Y-Q, Zhang C, et al. A bibliometric analysis using CiteSpace of publications from 1999 to 2018 on patient rehabilitation after total knee arthroplasty. Med Sci Monit 2020;26:e920795.

7 Chen C. CiteSpace II: detecting and visualizing emerging trends and transient patterns in scientific literature. J. Am. Soc. Inf. Sci. 2006;57:359-77.

8 Müller H, Kommescher M, Güttgemanns J, et al. Cognitive behavioral therapy in adolescents with early-onset psychosis: a randomized controlled pilot study. Eur Child Adolesc Psychiatry 2020;29:1011 1022.

9 Jones C, Hacker D, Cormac I, et al. Cognitive behavioral therapy plus standard care versus standard care plus other psychosocial treatments for people with schizophrenia. Schizophr Bull 2019;45:284-6.
10 Kennedy L, Xyrichis A. Cognitive behavioral therapy compared with Non-specialized therapy for alleviating the effect of auditory hallucinations in people with Reoccurring schizophrenia: a systematic review and meta-analysis. Community Ment Health $J$ 2017;53:127-33.

11 Spencer HM, McMenamin M, Emsley R, et al. Cognitive behavioral therapy for antipsychotic-free schizophrenia spectrum disorders: does therapy dose influence outcome? Schizophr Res 2018;202:385-6.

12 Morrison AP, Law H, Carter L, et al. Antipsychotic drugs versus cognitive behavioural therapy versus a combination of both in people with psychosis: a randomised controlled pilot and feasibility study. Lancet Psychiatry 2018;5:411-23.

13 AIRyalat SAS, Malkawi LW, Momani SM. Comparing bibliometric analysis using PubMed, Scopus, and web of science databases. $J$ Vis Exp 2019;152. doi:10.3791/58494

14 Eshraghi A, Osman NAA, Gholizadeh H, et al. 100 top-cited scientific papers in limb prosthetics. Biomed Eng Online 2013;12:119.

15 Alonso S, Cabrerizo FJ, Herrera-Viedma E, et al. h-Index: a review focused in its variants, computation and standardization for different scientific fields. J Informetr 2009;3:273-89.

16 Belter CW. Bibliometric indicators: opportunities and limits. J Med Libr Assoc 2015;103:219-21.

17 Chen C. The centrality of pivotal points in the evolution of scientific networks. San Diego, California, USA: ACM: Proceedings of the 10th international conference on Intelligent user interfaces, 2005: 98-105.

18 Xie P. Study of international anticancer research trends via co-word and document co-citation visualization analysis. Scientometrics 2015;105:611-22.

19 Gray R, Hassanein E, Thompson DR. Journal editors and their hindex. J Adv Nurs 2017;73:2031-4.

20 McGorry PD, Yung AR, Phillips LJ, et al. Randomized controlled trial of interventions designed to reduce the risk of progression to firstepisode psychosis in a clinical sample with subthreshold symptoms. Arch Gen Psychiatry 2002;59:921-8.

21 Sensky T, Turkington D, Kingdon D, et al. A randomized controlled trial of cognitive-behavioral therapy for persistent symptoms in schizophrenia resistant to medication. Arch Gen Psychiatry 2000;57:165-72.

22 Zimmermann G, Favrod J, Trieu VH, et al. The effect of cognitive behavioral treatment on the positive symptoms of schizophrenia spectrum disorders: a meta-analysis. Schizophr Res 2005;77:1-9.

23 Szigethy E, Kenney E, Carpenter J, et al. Cognitive-Behavioral therapy for adolescents with inflammatory bowel disease and subsyndromal depression. J Am Acad Child Adolesc Psychiatry 2007;46:1290-8.

24 Myin-Germeys I, Nicolson NA, Delespaul PA. The context of delusional experiences in the daily life of patients with schizophrenia. Psychol Med 2001;31:489-98.

25 Pruessner M, lyer SN, Faridi K, et al. Stress and protective factors in individuals at ultra-high risk for psychosis, first episode psychosis and healthy controls. Schizophr Res 2011;129:29-35.

26 Hatkevich C, Venta A, Sharp C. Theory of mind and suicide ideation and attempt in adolescent inpatients. J Affect Disord 2019;256:17-25.

27 Chien WT, Cheng HY, McMaster TW, et al. Effectiveness of a mindfulness-based psychoeducation group programme for earlystage schizophrenia: an 18-month randomised controlled trial. Schizophr Res 2019;212:140-9.

28 Perris F, Fabrazzo M, De Santis V, et al. Comorbidity of obsessivecompulsive disorder and Schizotypal personality disorder: clinical response and treatment resistance to pharmacotherapy in a 3-year follow-up naturalistic study. Front Psychiatry 2019;10:386.

29 Haddaway NR, Collins AM, Coughlin D, et al. The role of Google Scholar in evidence reviews and its applicability to grey literature searching. PLoS One 2015;10:e0138237.

30 Lepard JR, Walters BC. A bibliometric analysis of neurosurgical practice guidelines. Neurosurgery2019.

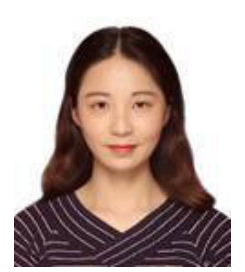

Xinxing Fei obtained a bachelor's degree in medicine in 2018 and began to study for a master's degree in the same year in Southwest Medical University, China. Meanwhile, she is also receiving the standardized training of resident doctors in the Department of Psychiatry and successfully obtained the qualification certificate of medical practitioners. Her main research interest includes schizophrenia. 